\title{
Wie ist der Urlaub bei Teilzeit geregelt?
}

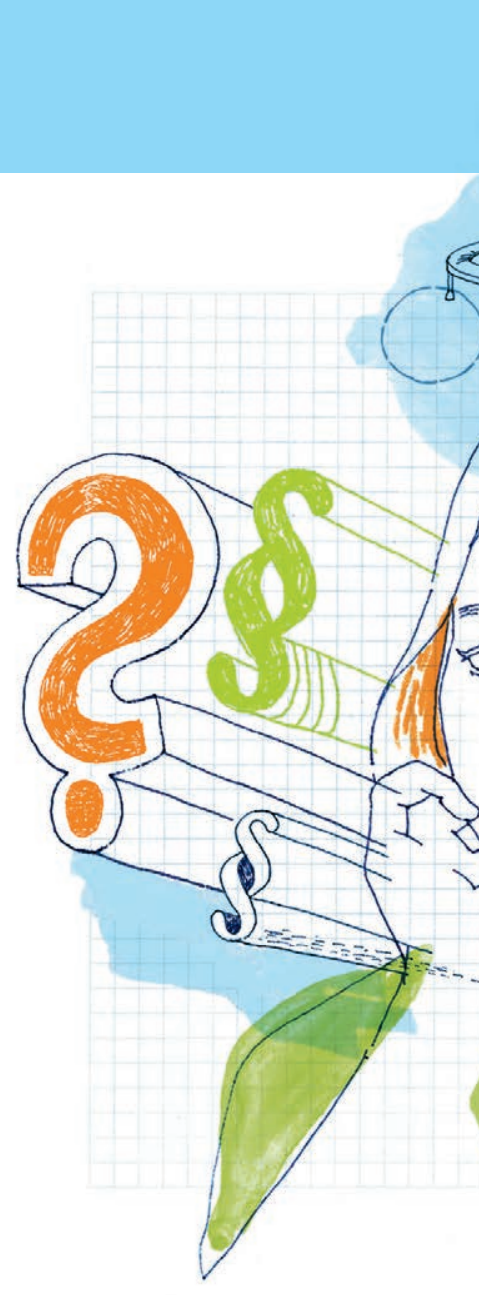

Die Rechtsfrage

" Ich arbeite Teilzeit und vier Tage pro Woche

von Montag bis Donnerstag. Für eine volle

Urlaubswoche zieht mir meine Chefin fünf Tage

ab. Nehme ich Donnerstag einen Tag frei, zieht

sie mir auch den Freitag von meinen insgesamt

20 Urlaubstagen ab. Ist das richtig? "

Therapeutin aus Berlin

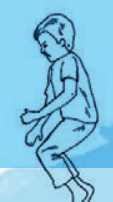

23
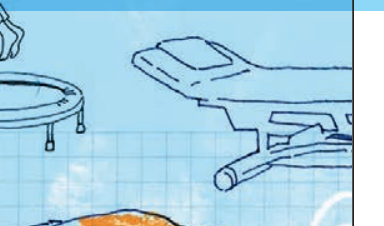

\section{Die Antwort unseres Experten}

Nach dem Bundesurlaubsgesetz steht jedem Arbeitnehmer ein Mindesturlaubsanspruch von 24 Werktagen bzw. vier Urlaubswochen zu. Werktage sind alle Tage, die nicht Sonntage oder gesetzliche Feiertage (im jeweiligen Bundesland) sind. Für die Berechnung des Urlaubsanspruchs geht man also von sechs Werktagen je Woche aus. Doch wie in Ihrem Fall wird nicht immer in einer Sechs-Tage-Woche gearbeitet. Das Bundesarbeitsgericht hat daher eine Formel zur Umrechnung des Urlaubsanspruchs entwickelt: Urlaubswochen mal Arbeitstage des Teilzeitbeschäftigten gleich Urlaubsanspruch in Tagen. Arbeitet eine Angestellte demnach fünf Tage je Woche, hat sie einen gesetzlichen Urlaubsanspruch auf 20 Arbeitstage. Arbeitet sie vier Tage je Woche, kann sie gesetzlichen Urlaub von 16 Tagen verlangen, bei drei Arbeitstagen 12 Tage usw. Urlaub muss sie für die Tage nehmen, an denen sie üblicherweise arbeitet.

In Ihrem Fall bedeutet dies, dass Sie nach dem Bundesurlaubsgesetz Anspruch auf 16 Urlaubstage im Jahr haben, da Sie vier Tage je Woche arbeiten. Urlaub müssen Sie nur dann beantragen, wenn Sie am Montag, Dienstag, Mittwoch oder Donnerstag freinehmen möchten. Freitag und Samstag haben Sie sowieso frei. In Ihrem Vertrag sind offenbar 20 Urlaubstage vereinbart. Wenn für beide Vertragspartner klar ist, dass dieser Urlaubsanspruch auf der FünfTage-Woche basiert, Sie jedoch nur 16 Urlaubstage erhalten sollen, könnte Ihre Chefin vier Freitage, die sowieso frei sind, als Urlaubstage „anschreiben“. Sie würden die Ihnen zustehenden 16 Urlaubstage weiterhin behalten und könnten sie auf Ihre vier Arbeitstage je Woche verteilen und die Lohnbuchhaltung müsste keine Einzelfälle berücksichtigen. Unter diesen Umständen wäre die Anrechnung von Urlaub an Freitagen also im Ergebnis nicht falsch.

Führt das Anrechnen von Freitagen auf den Urlaubsanspruch jedoch dazu, dass Ihnen weniger als 16 Urlaubstage verbleiben, die Sie auf Montag bis Donnerstag verteilen können, wäre die Anrechnungsmethode Ihrer Arbeitgeberin falsch.
„Pulver“ enthält Ihre Frage dahingehend, wie viel Urlaub tatsächlich vereinbart wurde. Aus dem schriftlichen Arbeitsvertrag muss klar hervorgehen, dass sich die 20 Urlaubstage auf eine Fünf-Tage-Woche beziehen. Sonst riskiert Ihre Chefin Streit. Arbeitgeber sollten insbesondere Teilzeitarbeitsverträge überprüfen, ob sich die getroffene Vereinbarung auch im schriftlichen Vertrag richtig und eindeutig wiederfindet.

Karsten Bossow

\section{$\Rightarrow$ Wirft auch Ihr Berufsalltag rechtliche Fragen auf? Dann schreiben Sie an Simone.Gritsch@thieme.de.}

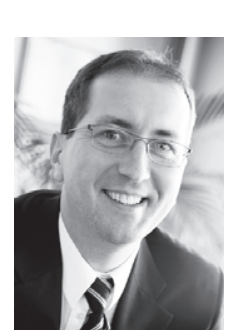

Karsten Bossow ist seit 1999 Rechtsanwalt mit den Tätigkeitsschwerpunkten Arbeits-, Medizin- und Sozialrecht. Seit 2003 ist er Fachanwalt für Medizinrecht. 